\title{
LAS AMENAZAS A LA DEMOCRACIA SEGÚN TOCQUEVILLE. LA „TIRANÍA DE LAS MAYORÍAS” EN LOS TIEMPOS ACTUALES
}

\author{
Marcelo Javier de los Reyes \\ Licenciado en Historia graduado en la Facultad de Filosofia y Letras de la Universidad de Buenos Aires. \\ Doctorando en Ciencia Política en la Pontificia Universidad Católica Argentina. Presidente del Centro \\ de Estudios Internacionales para el Desarrollo (CEID), Buenos Aires, Argentina. jreyes1@ceid.edu.ar
}

Sirvo a la patria sin otro objeto que el de verla constituida, ése es el premio al que aspiro.

Manuel Belgrano

Hablemos claro mi amigo creo que estamos en una verdadera anarquía, o por lo menos una cosa muy parecida a esto ;carajo con nuestros paisanitos!, toda liberalidad, y con ella nos vamos al sepulcro. En tiempo de revolución no hay más medio para ejecutarla que el que manda diga hágase, que esto se ejecute tuerto o derecho ...

Carta de José de San Martín a Tomás Guido 28 de enero de 1816

Resumen. En este se aborda la visión de Tocqueville respecto a las virtudes de la democracia en los Estados Unidos, particularmente respecto a la „,igualdad de condiciones” pero también se refiere a las amenazas que pueden afectar a esa forma de gobierno: la posibilidad de caer en el despotismo y la tiranía de las mayorías.

A partir de ese punto analiza cómo estas dos amenazas avanzan en las democracias americanas y, en la actualidad, han dado lugar a que se hable de „,neopopulismos”, lo que alude a la existencia de gobiernos de neto corte populista en el pasado. Varias naciones de América atravesaron por esa forma de hacer política, la cual ha dejado serias secuelas tanto en los partidos políticos, en las instituciones como en las respectivas sociedades. Luego de superar los gobiernos militares que dominaron la vida política de la región y tras el retorno de la democracia, el autor considera que el populismo se conquistó nuevamente en la forma de gobernar en numerosos países.

Palabras clave: Tocqueville, democracia, cesarismo, populismo, neopopulismo

\section{INTRODUCCIÓN}

En la primera parte del presente trabajo abordo la visión de Tocqueville respecto a las virtudes de la democracia en los Estados Unidos - autodenominada „América" - particularmente respecto a la ,igualdad de condiciones". No obstante, advirtió que esa forma de gobierno contiene, en sí misma, la posibilidad de caer en el despotismo y en la tiranía de las mayorías. 
En la segunda parte analizo cómo estas dos amenazas a la democracia despotismo y tiranía de las mayorías ${ }^{1}$ - avanzan en las democracias americanas. En la actualidad se habla de „neopopulismos”, lo que alude a la existencia de gobiernos de neto corte populista en el pasado. Varias naciones de América atravesaron por esa forma de hacer política, la cual ha dejado serias secuelas tanto en los partidos políticos como en las respectivas sociedades. El populismo se enquistó nuevamente en la forma de gobernar tras el retorno de la democracia en numerosos países que padecieron regímenes militares.

Se entiende por populismo las prácticas de gobierno que se orientan a satisfacer los deseos de las mayorías logrando, en contrapartida, su apoyo para la gestión de gobierno. Para ello el gobernante apela a su carisma haciendo uso de los sentimientos y pasiones que se despiertan en el gobernado, es decir, en el „pueblo”. Si bien el concepto de „pueblo” parece expresar la totalidad de la población de un país, la realidad es que se trata de una parte de ella que no necesariamente tiene que ser la mayoría pero que sí precisa del silencio de buena parte de la sociedad. El populismo no puede ser imaginado como algo que emana de abajo hacia arriba sino que es una figura fuerte que apela a los sentimientos de una parte considerable del ,pueblo”, por lo que se impone desde el propio ejercicio del poder. El profesor Guillermo O'Donnell hablaba de una modalidad de la democracia que él denomina „democracia delegativa”, concepto que encierra a la conjunción del ,personalismo" y del ,populismo” y que llega al gobierno a través del ejercicio democrático, es decir, mediante el sufragio popular ${ }^{2}$. De ese modo, la democracia representativa deriva en una „democracia delegativa", habida cuenta de que el gobernante asume que, al ser elegido por la mayoría, posee toda la autoridad que le ha sido delegada para aplicarla en su gestión de gobierno. La idea del „personalismo” nos retrotrae al „caudillismo” que se ha encarnado en la historia americana desde los tiempos inmediatamente posteriores a la independencia.

A pesar de coincidir con el concepto de „democracia deliberativa” prefiero considerar a estos gobiernos tomando el término utilizado por el venezolano Laureano Vallenilla Lanz: cesarismo democrático. El concepto de cesarismo suele ser atribuido a Gramsci, para quien „expresa siempre la „solución 'arbitraria', confiada a una gran personalidad, de una situación histórico-política caracterizada por un equilibrio de fuerzas de perspectiva catastrófica" ${ }^{3}$. También hizo una diferenciación entre un cesarismo progresista y uno regresivo pero lo cierto es que estas definiciones fueron plasmadas en sus escritos realizados entre

\footnotetext{
${ }^{1}$ En América Latina, dentro del concepto de despotismo se han dado los particularismos de cesarismo, populismo, autocracia y oclocracia.

${ }^{2}$ Guillermo A. O'Donell, Delegative Democracy, en: Journal of Democracy, 1994, vol. 5, no 1, p. 55-69.

3 Antonio Gramsci, El Cesarismo, en: Antonio Gramsci, <http://www.gramsci.org.ar/8/50.htm> [consulta; 10/10/2012].
} 
1932 y 1934, mientras que Laureano Vallenilla Lanz publicó su libro en 1919. También Pierre-Joseph Proudhon utilizó el término para titular su obra Césarisme et Christianisme, un ensayo de 1860.

Al analizar la forma de gobierno en varios países de la región se observa una tendencia hacia una autocracia propia del César en la que, incluso en algunos casos, pareciera que los ,aptos para gobernar” son los que pertenecen a la familia del autócrata, por lo que se procuran los mecanismos necesarios para asegurar la sucesión del gobierno.

Por tal motivo, si bien coincido con los conceptos de ,populismo” y de „democracia delegativa”, entiendo que el de „cesarismo” se adecua más para definir la forma de gestionar el gobierno por parte de varios líderes americanos.

Deseo hacer una salvedad respecto a la mención, más adelante, del gobierno de Rafael Leónidas Trujillo, ya que no sería un ejemplo que se encuadre en el concepto de „cesarismo democrático” sino de un autócrata, cuya sombra se proyectó en detrimento de la democracia dominicana y contribuyó como tantos otros - a crear la imagen en el colectivo de las sociedades americanas de que el caudillo es quien puede aportar las soluciones en los momentos de crisis.

\section{LA „IGUALDAD DE CONDICIONES”}

En oportunidad de su viaje a los Estados Unidos, en 1831-1832, el aristócrata francés Alexis de Tocqueville fue sorprendido por lo que denominó ,la igualdad de condiciones" que encontró en ese país. A su juicio, nada lo sorprendió más y lo expresó de la siguiente manera en su libro La democracia en América, publicado en 1835-1840:

Así, pues, a medida que estudiaba la sociedad norteamericana, veía cada vez más, en la igualdad de condiciones, el hecho generador del que cada hecho particular parecía derivarse, y lo volvía a hallar constantemente ante mí como un punto de atracción hacia donde todas mis observaciones convergían ${ }^{4}$.

Tocqueville, que provenía de una familia aristocrática que gozó de los tiempos previos a la revolución - los tiempos de la „sociedad aristocrática” admiró la igualdad y la libertad que encontró al visitar los Estados Unidos y ponderó ese estado democrático. Allí se plasmó un Estado que hasta ese momento sólo existía intelectualmente, pues en Francia la revolución no había podido lograrlo, a pesar de los lineamientos que desarrollaron los filósofos franceses de la Ilustración. A tal punto llegó esa admiración por parte de Tocqueville que expresó que, en los Estados Unidos, la igualdad de condiciones

\footnotetext{
${ }^{4}$ Alexis de Tocqueville, La democracia en América. México, Fondo de Cultura Económica, 2009, p. 31 .
} 
había alcanzado „límites extremos”. Se trataba de un fenómeno político nuevo en un país nuevo en el Nuevo Mundo. La sociedad estadounidense de la colonia no había sido testigo de la "sociedad aristocrática" que era tradicional en Europa y cuya concepción impedía contemplar los cambios que se estaban operando en ese continente.

En Francia, la Revolución y la Ilustración no habían llegado a tanto. Aún más, el camino en el viejo mundo aún se percibía incierto. Sin embargo, el pasaje hacia la igualdad y hacia la democracia ya se había iniciado aunque el destino de la humanidad, o del mundo cristiano - como bien precisa Tocqueville cuando dice que la misma revolución "continúa a través del universo cristiano" dudoso para su época. Él mismo, en la introducción se pregunta „¿A dónde vamos?". Se responde:

Nadie podría decirlo; los términos de comparación nos faltan; las condiciones son más iguales en nuestros días entre los cristianos, de lo que han sido nunca en ningún tiempo ni en ningún país del mundo; así la grandeza de lo que ya está hecho impide prever lo que se puede hacer todavía ${ }^{7}$.

Esta era una nueva etapa de la igualdad que seguía al que había observado en la Iglesia:

Pero he aquí el poder político del clero que acaba de fundarse y que muy pronto va a extenderse El clero abre sus filas a todos, al pobre y al rico, al labriego y al señor; la igualdad comienza a penetrar por la Iglesia en el seno del gobierno, y aquel que hubiera vegetado como un siervo en eterna esclavitud, se acomoda como sacerdote entre los nobles, y a menudo se sitúa por encima de los reyes ${ }^{8}$.

La emigración europea fue motivada por razones religiosas, políticas y como consecuencia de la pobreza, lo cual garantizaba - según Tocqueville - la emergencia de una nueva sociedad basada en la igualdad ${ }^{9}$. Se abría entonces un espacio para una nueva libertad, la libertad burguesa, que daría contenido a la sociedad capitalista. Este enfrentamiento entre el Ancien régime - es decir, el sistema de gobierno anterior prerrevolucionario que no sólo imperaba en Francia sino también en el resto de las monarquías europeas - y la nueva sociedad emergente es el tema central de Tocqueville pero también una tendencia universal, como bien lo indica el historiador estadounidense Thomas Bender:

\footnotetext{
${ }^{5}$ En una comparación con Europa, expresa: „Entonces transporté mi pensamiento hacia nuestro hemisferio, y me pareció percibir algo análogo al espectáculo. Vi la igualdad de condiciones que, sin haber alcanzado como los Estados Unidos sus límites extremos, se acercaba a ellos cada día más a prisa; y la misma democracia, que gobernaba las sociedades norteamericanas, me pareció avanzar rápidamente hacia el poder en Europa". Alexis de Tocqueville, op. cit., p. 31.

${ }^{6}$ Ibidem, p. 33.

7 Ídem.

${ }^{8}$ Ibidem, p. 31.

9 „No son por cierto los más felices y poderosos quienes se destierran, y la pobreza, así como la desgracia, son las mejores garantías de igualdad que se conocen entre los hombres." Ibidem, p. 55.
} 
En el mundo noratlántico, las oposiciones a las antiguas formas sociales y a los valores culturales imperiales fueron en parte impulsadas por el individualismo en boga, que estas a su vez promovían. La época de la revolución fue, como señaló en repetidas ocasiones Alexis de Tocqueville en sus clásicos trabajos sobre la Revolución Francesa y la democracia en Norteamérica, parte de una historia más amplia del individualismo moderno que reivindicaba los conceptos de igualdad y autonomía. Si bien no podemos decir lo mismo de los valores que impulsaron a Mehmet Alí en Egipto o a Tupac Amaru en Perú, ese sentimiento fue evidente en muchas crisis, incluidas otras que se produjeron en los imperios otomano y español. Con algunas excepciones, hay una amplia narrativa histórica que apoya la revolución estadounidense y los demás conflictos y revoluciones contemporáneos, en particular aquellos que reivindicaron los derechos humanos universales ${ }^{10}$.

Del mismo modo, debe mencionarse que desde la Revolución Francesa - y con mayor énfasis hacia mediados del siglo XIX - se asistía a un fuerte conflicto entre la autoridad central y la resistencia a ceder la autonomía local, es decir, la autoridad regional o la comuna. Era la crisis federal que también puede encontrarse en otras historias nacionales, como por ejemplo la historia argentina, desde mediados del siglo XIX. Por esos años, los Estados Unidos ya se habían extendido hacia el sur, a costa de México, y hacia el oeste incorporando nuevos territorios a la nación, acorde al sentimiento nacionalista estadounidense, entendido ya como una ideología.

\section{LAS AMENAZAS A LA DEMOCRACIA}

A pesar de su admiración por esa „sociedad democrática”, Tocqueville advirtió que la democracia presentaba dos peligros: por un lado, la „tiranía de la mayoría” y, por el otro, el „despotismo".

En el marco de estas prevenciones que hace acerca de la democracia, considera que el gran riesgo de este sistema reside en el hecho de que favorece la igualdad, pero suprime la libertad. De tal manera que el mayor peligro que puede derivarse de una democracia sin contrapesos es el despotismo o la tiranía. La observación de las sociedades modernas lo llevó a prevenir la inminencia de un nuevo despotismo que se originaría, precisamente, en el seno de las sociedades democráticas y que amenazaría con destruirlas.

De esa manera se caería en un despotismo democrático pero que, afortunadamente, tal situación no sería irreversible. Para recuperar o defender la libertad amenazada se hace necesario combatir las nefastas tendencias del individualismo.

La democracia constituye el ideal de la forma de gobierno pero requiere que los poderes estén en permanente equilibrio porque, de lo contrario, podría derivar en una tiranía similar a la del absolutismo. La democracia, como fin,

\footnotetext{
${ }^{10}$ Thomas Bender, Historia de los Estados Unidos. Una nación entre naciones. Buenos Aires, Siglo Veintiuno Editores, 2011, p. 86.
} 
apunta a la libertad de los individuos pero corre el riesgo de que la mayoría imponga su voluntad en perjuicio de las minorías si no se limita su poder.

En este sentido, expresa Tocqueville:

Considero como impía y detestable la máxima de que, en materia de gobierno, la mayoría de un pueblo tiene derecho a hacerlo todo y, sin embargo, sitúo en la voluntad de la mayoría el origen de todos los poderes ¿Estoy en contradicción conmigo mismo ${ }^{11}$

Luego agrega que la justicia es la ley general adoptada por la mayoría de todos los hombres y que ,una nación es como un jurado encargado de representar a la sociedad universal y de aplicar la justicia, que es su ley"12. Cuando una ley es injusta y alguien se opone a obedecerla no está negando a la mayoría el derecho de mandar sino que se apela a la soberanía del pueblo ante la soberanía del género humano, dice Tocqueville. Era consciente de los abusos en que se había caído como consecuencia de la Revolución francesa y durante el régimen de Napoleón - invocando la soberanía popular. Los excesos de esa soberanía habían puesto en peligro la libertad.

Según Tocqueville la mayoría, tomada colectivamente, no es más que „un individuo que tiene opiniones y muy a menudo intereses contrarios a otro individuo que se llama la minoría"13. Expresa que le reprocha al gobierno democrático de Estados Unidos „su fuerza irresistible” pero lo que más le „repugna” de ese país „no es la extremada libertad que allí reina” sino „la poca garantía que se tiene en contra de la tiranía". Este sentimiento se debe al hecho de que la opinión pública, el poder ejecutivo, la fuerza pública, el jurado y los jueces de ciertos Estados emanan de esa mayoría. La respuesta que da a esta situación es una democracia que cuente con una división de poderes que incluya un poder judicial independiente del legislativo y del ejecutivo. De tal modo se contaría con un gobierno democrático sin posibilidades de caer en una tiranía ${ }^{14}$. No obstante, reconoce la autoridad que les han concedido a los legistas en Estados Unidos y su influencia en el gobierno, elementos que constituyen una „poderosa barrera contra los extravíos de la democracia”" ${ }^{2}$. Es interesante citar el papel de los legistas en Estados Unidos, según Tocqueville:

Los legistas constituyen, en los Estados Unidos, un poder al que se teme poco, que apenas se percibe, que no tiene bandera propia, que se pliega con flexibilidad a las exigencias del tiempo y que se deja llevar sin resistencia por todos los movimientos del cuerpo social; pero envuelve a la sociedad entera, penetra en cada una de las clases que la componen, la trabaja en secreto, obra sin cesar sobre ella sin que se percate y acaba por modelarla según sus deseos ${ }^{16}$.

\footnotetext{
${ }^{11}$ Alexis de Tocqueville, op. cit., p. 257.

${ }^{12}$ Ídem.

${ }^{13}$ Ibidem, p. 258.

${ }^{14}$ Ibidem, p. 258-259.

${ }^{15}$ Ibidem, p. 267.

${ }^{16}$ Ibidem, p. 273.
} 
Tocqueville reconoce que hay tres causas principales que tienden a mantener la república democrática en los Estados Unidos: „la situación particular y accidental en la cual la Providencia ha colocado a los norteamericanos", „las leyes” y lo que emana de „los hábitos y de las costumbres”17. En el capítulo IX de la segunda parte de su libro, se aboca a argumentar estas tres causas.

De alguna manera, el profesor emérito de Sociología en la Universidad de Leeds y en la Universidad de Varsovia, Zygmunt Bauman, mantiene cierta coincidencia conceptual con la representación que Tocqueville hace de la sociedad democrática. En su libro Comunidad. En busca de seguridad en un mundo hostil parte de la base conceptual que el término „comunidad” produce una „sensación” positiva; dice que ,tenemos el sentimiento de que la comunidad es siempre algo bueno" ${ }^{18}$. Nos refiere a un lugar „cálido”, que nos brinda seguridad, protección de los peligros que acechan por fuera de ella.

De alguna manera, Bauman refiere a la „comunidad” tocquevilliana formada por quienes emigraron a América. Tocqueville, en el capítulo V, titulado „Necesidad de estudiar lo que sucede en los Estados antes de hablar del gobierno de la Unión” distingue „dos gobiernos separados y casi independientes”: uno que responde a las necesidades cotidianas de la sociedad y otro, al que considera „excepcional y circunscrito", que se aplica a ciertos intereses generales ${ }^{19}$. En este punto destaca la „sociedad comunal” que, a diferencia de los reinos y de las repúblicas, que son creaciones del hombre, la comuna ,parece salir directamente de las manos de Dios”.20. Agrega que en la comuna „reside la fuerza de los pueblos libres"21. Para ejemplificar el funcionamiento del gobierno comunal toma como modelo la comuna de la Nueva Inglaterra y la siguiente cita es relevante para manifestar el sentimiento que se encuentra en la misma:

El habitante de la Nueva Inglaterra se arraiga a su comuna, no tanto por haber nacido en ella, como porque ve en esa comuna una corporación libre y fuerte de la que forma parte, que merece la pena sea bien dirigida.

Acontece a menudo, en Europa, que los gobernantes mismos echan de menos la ausencia de espíritu comunal; porque todos convienen en que el espíritu comunal es un gran elemento de orden y de tranquilidad pública, pero no saben cómo producirlo. Al volverse la comuna fuerte e independiente, temen fragmentar el poder social y exponer al Estado a la anarquía. Ahora bien, quitad la fuerza y la independencia de la comuna y sólo encontraréis en ella administrados y nunca ciudadanos $^{22}$.

Esta cita es relevante porque refiere a esa tranquilidad, a esa protección, a ese lugar donde las reglas de juego entre sus habitantes son claras, virtudes que, de alguna manera, son las que nos brindan esa „calidez” a las que se refiere

${ }^{17}$ Ibídem, p. 278.

${ }^{18}$ Zygmunt Bauman, Comunidad. En busca de seguridad en un mundo hostil, Buenos Aires, Siglo XXI de Argentina Editores, p. 7.

${ }^{19}$ Alexis de Tocqueville, op. cit., p. 77.

${ }^{20}$ Ibidem, p. 78.

${ }^{21}$ Ídem.

${ }^{22}$ Ibídem, p. 83. 
Bauman. Quien reside en la comuna se siente „ciudadano” y es muy diferente al sentimiento de ,administrado" que se puede encontrar en el marco del gobierno federal - incluso en los Estados Unidos - o de las naciones europeas. Estos „ciudadanos" se interesan por la cosa pública ya que pueden percibirla como algo próximo, cercano, y „en cierto modo a cada instante" ${ }^{23}$. La comuna, esencialmente, pone a los hombres en pie de igualdad, lo que permite que cualquiera de sus integrantes pueda contribuir en su administración.

Sin embargo, en la actualidad, la „comunidad” es un concepto inasible, algo de lo que hablamos pero a lo que, en verdad, no podemos acceder. Bauman cita a Raymond Williams, quien considera que la comunidad es algo que „siempre ha sido" ${ }^{24}$. En este sentido, el académico polaco destaca que en la comunidad se pretende gozar de „libertad" y „seguridad" pero que en realidad estos valores son contradictorios como los de „comunidad” e ,individualidad”. Cito a Bauman:

Promover la seguridad siempre exige el sacrificio de la libertad, en tanto que la libertad sólo puede ampliarse a expensas de la seguridad. Pero seguridad sin libertad equivale a esclavitud (y, además, sin una inyección de libertad, a fin de cuentas demuestra ser un tipo de seguridad sumamente inseguro); mientras que la libertad sin seguridad equivale a estar abandonado y perdido (y, a fin de cuentas, sin una inyección de seguridad, demuestra ser un tipo de libertad sumamente esclava). Esta circunstancia ha procurado a los filósofos una jaqueca sin cura conocida. También determina que convivir sea tan conflictivo, puesto que la seguridad sacrificada en aras de la libertad tiende a ser la seguridad de otra gente; y la libertad sacrificada en aras de la seguridad tiende a ser la libertad de otra gente ${ }^{25}$.

En este párrafo Bauman introduce una palabra clave que es „convivir” y muestra la „convivencia” como algo „conflictivo”. De alguna manera, esa „convivencia conflictiva” se percibe en la sociedad democrática entre la mayoría y la minoría, en particular, cuando la primera - apelando a la fuerza de su número - se impone sin miramientos sobre la segunda.

\section{UNA APROXIMACIÓN AL CESARISMO}

Tocqueville se esforzó en mostrar, a través de su obra, que el rumbo político de su tiempo se encaminaba hacia la democracia, la que giraba en torno de la libertad individual, para lo cual debía contemplarse la división de poderes, una participación de los ciudadanos en pro de una conciencia cívica y una descentralización de la política que aleje la amenaza del cesarismo, encarnado en su época por Napoleón III.

\footnotetext{
${ }^{23}$ Ibidem, p. 84

${ }^{24}$ Zygmunt Bauman, op. cit., p. 9.

${ }^{25}$ Ibidem, p. 27.
} 
Tocqueville percibía que la democracia moderna podía encaminarse hacia la tiranía de la mayoría, la cual podía derivar en demagogia $(\delta \eta \mu \alpha \gamma \omega \gamma i ́ \alpha=$ degeneración de la democracia, consistente en que los políticos, mediante concesiones y halagos a los sentimientos elementales de los ciudadanos, tratan

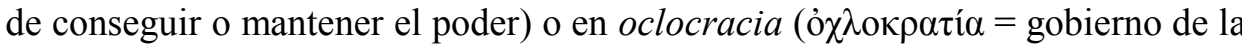
muchedumbre o de la plebe).

El cesarismo requiere de una personalidad fuerte que ejerza los poderes públicos para brindar respuestas arbitrarias, más aún cuando existen instituciones débiles. América ${ }^{26}$ ha sido y es una región proclive a la emergencia de figuras fuertes que apelan a la demagogia. En el pasado encontramos, en Venezuela, al régimen de Juan Vicente Gómez quien, como resultado de las luchas personalistas por el control del poder, ejerció la presidencia entre 1908 y 1935. Laureano Vallenilla Lanz, uno de sus ministros, fue quien incubo el concepto de „cesarismo democrático”, en un libro publicado en 1919. En el mismo ofrece una caracterización de la democracia:

Lo que caracteriza esencialmente la democracia, ha escrito Robert Michels, el eminente profesor de la Universidad de Turín, repitiendo una frase célebre, es que bajo su imperio, cada quien lleva en la mochila un bastón de mariscal y hablando de Venezuela, un escritor colombiano, el doctor Ricardo Becerra parodió ese concepto diciendo, que desde la guerra de Independencia el bastón del magistrado andaba en la capotera del recluta ${ }^{27}$.

Es interesante la cita en la que define tanto a quien ejerce el „cesarismo democrático" como a ese concepto mismo:

El César democrático, como lo observó en Francia un espíritu sagaz, Eduardo Laboulaye, es siempre el representante y el regulador de la soberanía popular. „El es la democracia personificada, la nación hecha hombre. En él se sintetizan estos dos conceptos al parecer antagónicos: democracia y autocracia", es decir: Cesarismo Democrático; la igualdad bajo un jefe; el poder individual surgido del pueblo por encima de una gran igualdad colectiva, reproduciendo en esta antigua colonia española, por raras coincidencias sociológicas, el mismo régimen de gobierno que un ilustre historiador lusitano considera como el ideal de la raza ibérica, cuando bajo la autoridad de uno solo se fundieron las nacionalidades peninsulares, la guerra fue una escuela de igualación social, el pueblo conquistó las más altas prerrogativas, se eliminaron los privilegios, se abatieron los grandes y se estableció el más perfecto acuerdo entre el espíritu nacional y las instituciones surgidas naturalmente de la evolución orgánica, que fueron por esa causa la genuina expresión del genio colectivo, dando a España la unidad y la fuerza necesarias para imponer al mundo su voluntad y su pensamiento" 28 .

\footnotetext{
${ }^{26}$ Como no soy partidario del uso del término „Latinoamérica” o „América Latina” prefiero hablar de América. No obstante, respeto su uso en las citas de otros autores. Al respecto ver: Marcelo Javier de los Reyes, América sigue sin definir su identidad, en: Centro de Estudios Internacionales para el Desarrollo (CEID), 14/02/2011, <http://www.ceid.edu.ar/biblioteca/2011/marcelo_javier_de_los_reyes america sigue sin definir_su identidad.pdf $>$, [consulta: 10/12/2012].

${ }^{2 \overline{7}}$ Laureaño Vallenilla Lanz, Cesarismo democrático. Estudios sobre las bases sociológicas de la constitución efectiva de Venezuela, Caracas, Empresa El Cojo, 1919, p. 302.

${ }^{28}$ Ibidem, p. 303-304.
} 
De ese modo, en América, de la mano de Laureano Vallenilla Lanz, apareció el término „cesarismo democrático”, que caracteriza a un gobierno basado en la reelección permanente de un líder carismático, capaz de concentrar un gran poder. Se trata de un conductor que busca legitimarse a través del sufragio popular. Respecto del concepto es relevante la conjunción de „democracia y autocracia”.

Se trata de una significación que ha permitido y que permite precisar la peculiaridad de varios gobiernos a lo largo de la historia del continente pero, en especial, en el momento actual. De esa manera, se prosigue con una fuerte adhesión al caudillo local, a quien se percibe como la persona capaz de responder a los reclamos de los sectores más desprotegidos de la sociedad. Esta admiración por los líderes carismáticos parecería estar enraizada en la idiosincrasia de buena parte de las sociedades americanas

\section{AMÉRICA ENTRE LA DEMOCRACIA Y EL CESARISMO}

De ese modo, la historia reciente y los tiempos actuales de América cuentan con numerosos ejemplos. El impulso de perpetuarse en el poder, obviando lo ordenado por la Constitución, ha sido una gran tentación de varios presidentes americanos durante el siglo XX, que ha continuado hasta en estos primeros años del siglo XXI.

En la historia de la República Dominicana se encuentra uno de esos ejemplos. Entre los años 1916 y 1924, los Estados Unidos ocuparon el país e instituyeron un protectorado, en el marco del cual crearon la Guardia Nacional. De esa fuerza emergió la figura de Rafael Leónidas Trujillo, quien era jefe del Estado Mayor y se apropió del poder en 1930. Con el respaldo del gobierno estadounidense rigió los destinos del país de forma dictatorial, aún cuando ocasionalmente - no ejercía nominalmente la presidencia. Finalmente murió asesinado en mayo de 1961, cerrando un ciclo que se inició con su ascenso al poder y dando inicio a un convulsionado período democrático luego de una rebelión popular, liderada por Manuel Aurelio „Manolo” Tavárez Justo, jefe de la „Agrupación política 14 de junio”, excarcelado tras la muerte de Trujillo. En 1963 se llevaron a cabo las primeras elecciones democráticas en las que fue elegido presidente el escritor Juan Bosch. Sin embargo, siete meses después, un golpe de Estado lo destituyó y los militares herederos de la dictadura de Trujillo se hicieron con el poder. En abril de 1965 los marines de Estados Unidos volvieron a la República Dominicana para poner fin a una rebelión popular capitaneada por el coronel Francisco Caamaño Deñó, bajo el pretexto de sus simpatías hacia Fidel Castro y el comunismo.

En la historia política venezolana el cesarismo fue encarnado por el mencionado Juan Vicente Gómez pero también por el general de división 
Marcos Pérez Jiménez, el trigésimo séptimo presidente, quien gobernó entre 1952 y 1958. En diciembre de 1952 la Junta de Gobierno lo designó provisionalmente para ese cargo, reemplazando a Germán Suárez Flamerich. En abril del año siguiente, la Asamblea Nacional Constituyente lo nombró presidente constitucional. Golpista por vocación, contribuyó a la caída del gobierno del general Isaías Medina - el 18 de octubre de 1945 -, quien deseaba establecer las bases de un sistema democrático. En noviembre de 1948 participó del derrocamiento del gobierno de Rómulo Gallegos, elegido como sucesor de la Junta Revolucionaria presidida por Rómulo Betancourt. Pérez Jiménez contemporáneo de Juan Domingo Perón y de Getúlio Vargas, referentes del populismo en Argentina y Brasil, respectivamente, hoy es recordado con nostalgia por algunos que comparan el gobierno de Hugo Chávez con el suyo, poniendo en evidencia las obras de infraestructura levantadas en la década de 1950, así como sus políticas populistas. No obstante, se trató de un gobierno que - como tantos otros de corte populista - se mantuvo en el poder gracias a un fuerte aparato de represión.

En 1958 Venezuela comenzó a transitar por la democracia con referentes de partidos políticos que hicieron uso de discursos populistas e instauraron políticas de gobierno que giraron en torno del asistencialismo y del paternalismo. Como expresa el profesor en comunicación Reinaldo Cortés, „,se establece un hacer político con base en elementos nacionales con altas dosis de emocionalidad" ${ }^{\prime 29}$.

Hugo Chávez Frías procuró seguir el ejemplo dado por Juan Vicente Gómez a principios del siglo XX. El 4 de febrero de 1992, a la sazón un desconocido teniente coronel del ejército, lideró el frustrado golpe militar que dejó un saldo de cien muertos y que puso en peligro la vida del presidente Carlos Andrés Pérez, al atacar con morteros la Residencia de La Casona.

El entonces ministro de Defensa de Venezuela, Fernando Ochoa Antich, se expresa acerca de la emergencia de Chávez a partir del golpe de 1992 y del espíritu conspirativo de las fuerzas armadas:

La responsabilidad de las Fuerzas Armadas es indiscutible. Hugo Chávez se formó en sus filas. La insurrección militar de 1992 lo colocó en primer plano nacional. En algunas oportunidades he sostenido que las Fuerzas Armadas no aceptaron voluntariamente el régimen democrático. El triunfo de Rómulo Betancourt siempre lo consideraron una derrota. Los militares venezolanos han estado convencidos de que tienen el derecho de dirigir a Venezuela. Esa es la verdad. Ese sentimiento generalizado facilitó los intentos conspirativos que se originaron en su seno. El éxito de los primeros veinte años de vigencia de la democracia permitió un importante proceso de institucionalización de las Fuerzas Armadas que parecía indicar que la tendencia conspirativa había sido superada. Así lo percibió la dirigencia política de los partidos democráticos ${ }^{30}$.

${ }^{29}$ Reinaldo Cortés, Análisis de la estrategia discursiva de Hugo Chávez de cara a la creación del PSUV, en: „Disertaciones” (Anuario electrónico de estudios en Comunicación Social), ISSN-e 1856-9536, 1, 1, 2008 (Ejemplar dedicado a: Periodismo y Política).

${ }^{30}$ Fernando Ochoa Antich, Así Se Rindió Chávez: La Otra Historia Del 4 de Febrero. Caracas, El Nacional, 2007, 348 p. 
El 27 de noviembre del mismo año fue perpetrado un nuevo golpe de Estado, esta vez a cargo de oficiales de alta graduación y civiles pertenecientes a organizaciones revolucionarias y a grupos opuestos al gobierno del presidente constitucional Carlos Andrés Pérez. Esta sublevación estaba en sintonía con la del 4 de febrero liderada por Chávez pero de la que participaron oficiales de graduación media. Una evaluación no oficial estimó los muertos en más de trescientos. El gobierno pudo controlar rápidamente la situación y los involucrados en el fracasado golpe se rindieron o emprendieron la huida encontrando asilo en Perú, donde fueron recibidos por el gobierno de Alberto Fujimori en calidad de „perseguidos políticos” (93 insurrectos: 41 oficiales, 37

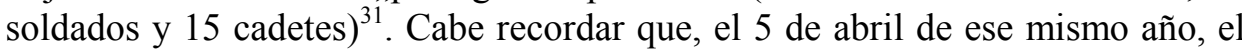
presidente peruano protagonizó un autogolpe con el respaldo de las fuerzas armadas y procedió a disolver el Congreso de la República y a intervenir el Poder Judicial. Del mismo modo, llevó a cabo una persecución a los miembros de la oposición. Paradójicamente, en su momento, un altísimo porcentaje de la población, avaló el autogolpe argumentando que el Congreso era una entidad corrupta que sólo obstaculizaba el accionar del Poder Ejecutivo. En su mensaje a la nación, el 5 de abril de 1992, Fujimori expresó el por qué de esa medida:

Durante estos veinte meses mi Gobierno se propuso la construcción de una democracia real, de una democracia que garantizara efectivamente la participación, en igualdad de condiciones, de todos los ciudadanos, en la que no haya lugar para el privilegio y la prebenda; y que realmente nos permitiera vencer, en el mediano plazo, el atraso, la miseria, la falta de oportunidades, la corrupción y la violencia ${ }^{32}$.

No podría afirmar que Fujimori haya leído a Tocqueville por haberse referido a la ,igualdad de condiciones” pero sí que su gobierno derivó hacia una dictadura, cercenando las libertades civiles, violando los derechos humanos e introduciendo la corrupción en todos los estamentos del poder. Actualmente se encuentra en prisión por ordenar el asesinato de nueve estudiantes y un profesor de la Universidad La Cantuta y de un grupo de personas de Barrios Altos en Lima, entre ellos un menor de 8 años. En 1993 fue promulgada una nueva Constitución, redactada por el Congreso Constituyente Democrático convocado por el mismo Fujimori tras la disolución del Congreso y aprobada mediante el referéndum de 1993. Esta Carta Magna mantuvo el mandato presidencial en cinco años pero permite una sola reelección inmediata o consecutiva (artículo 112).

31 Golpistas: Tal día como hoy Fujimori dio 93 asilos a venezolanos, „Reportero24”, 01/12/2010, <http://www.reportero24.com/2010/12/golpistas-tal-dia-como-hoy-peru-dio-93-asilos-avenezolanos/>, [consulta: 10/12/2012].

${ }^{32}$ Mensaje a la Nación del Presidente del Perú, Ingeniero Alberto Fujimori Fujimori, el 5 de abril de 1992, en: Congreso de la República, <http://www.congreso.gob.pe/museo/mensajes/Mensaje-1992-1.pdf>, [consulta: 10/12/2012]. 
Es relevante destacar que, veinte años después del golpe, una encuesta realizada por Ipsos Apoyo, reveló que 4 de cada 10 peruanos considera que el golpe de Estado de 1992 fue una medida necesaria ${ }^{33}$.

Este paréntesis que alude al caso peruano constituye, asimismo, un elemento relevante para considerar la valoración de la democracia por parte de los gobiernos y de la población de la región durante la década de 1990.

Con respecto a Venezuela, el 2 de febrero de 1999, como resultado del hartazgo de los venezolanos respecto del sistema de partidos - situación de cansancio que también fue alimentada desde los medios - Hugo Chávez asumió la presidencia mediante el sufragio popular, manteniendo el cargo hasta su muerte, acaecida el 5 de marzo de 2013, y dejando como sucesor a Nicolás Maduro. Durante estos años se procedió a la derogación de la Carta Magna de 1961, sobre la que había jurado Chávez, y a la promulgación de una nueva Constitución - en el mismo año de su asunción al cargo, en 1999. Muchos miembros de las fuerzas armadas ocuparon cargos dentro de los diversos estamentos del Estado venezolano, por lo que se observa una militarización de su gobierno.

Bajo el paraguas de la nueva Constitución, el 30 de julio de 2000, se llevaron a cabo las elecciones generales para "relegitimar todos los poderes”. Chávez obtuvo el 59,76\% de los votos y en 2001 inició su segundo período de gobierno.

El 12 de abril de 2002 ciertos sectores de la sociedad llevaron a cabo un golpe de Estado contra el gobierno de Chávez. La sublevación de las fuerzas armadas fue liderada por el general Efraín Vásquez, quien designó como jefe del gobierno de transición a un civil, Pedro Carmona Estanga, presidente de la patronal venezolana (Fedecámaras). En ese momento, el diario El País de España $^{34}$ se refirió al golpe diciendo que „ha puesto fin al sueño de una retórica revolución bolivariana encabezada por un ex golpista que ganó legítimamente las elecciones para convertirse desde el poder en un autócrata peligroso para su país y el resto del mundo"35. Se trataba del mismo Chávez al que, en 1999, el presidente del gobierno español, José María Aznar, recibiera en Madrid afirmando su „profunda confianza” en él ${ }^{36}$.

Sólo cuarenta y ocho horas le bastaron a Chávez para recuperar el poder. A pesar del quiebre de la sociedad venezolana a partir de abril de 2002, el 16 de agosto de 2004 obtuvo el respaldo del 58\% de los venezolanos en un referéndum revocatorio.

3320 años del golpe de Estado de Fujimori, en: No Apto Para Adultos (NAPA), $<$ http://napa.com.pe/2012/04/05/20-anos-del-golpe-de-estado-de-fujimori/>, [consulta: 10/12/2012].

${ }^{34}$ Ese mismo diario, en la madrugada del 24 de enero de 2013, fue el que publicó la falsa foto del presidente venezolano entubado durante su internación en Cuba.

35 Golpe a un caudillo, en: El País, 13/04/2002, <http://elpais.com/diario/2002/04/13/opinion/1018648802_850215.html>, [consulta: 15/12/2012].

${ }^{36}$ Ídem. 
El 3 de diciembre de 2006 se celebraron las elecciones presidenciales en las que fue reelegido con el 62,84\%. Asumió el 10 de enero de 2007 en el Capitolio Federal, oportunidad en la que anunció que llevaría a Venezuela por el camino de lo que denominó „Socialismo del siglo XXI”. Esta presentación ante la Asamblea Nacional fue acompañada de la expresión „Patria, Socialismo o Muerte” - lema que fue usado por políticos, legisladores, ministros e, incluso, en documentos oficiales -, frase que modificó en ocasión de celebrar su 57 cumpleaños, cuando se encontraba en tratamiento por su enfermedad, solicitando eliminar la palabra „muerte” e invocando a la vida con una nueva arenga: „Patria, socialista y victoria" ${ }^{\prime 3}$. Aprovechó para anunciar que se presentaría en las elecciones de 2012 y agregó: „Me atrevo a invitarlos a que celebremos en 10 años mis 67 (...). Yo no me voy en 2021 a lo mejor en 2031".

En las elecciones presidenciales para el período 2013-2019, celebradas el 7 de octubre de 2012, Chávez fue reelecto para un tercer mandato consecutivo pero pronto su salud decayó fuertemente y fue internado en Cuba. El 10 de enero de 2013 debió asumir nuevamente la presidencia pero, dos días antes, el presidente de la Asamblea Nacional, Diosdado Cabello, leyó un comunicado del vicepresidente de la República, Nicolás Maduro, que indicaba que Hugo Chávez, no podría estar en el acto de asunción y afirmó que el gobernante asumiría, posteriormente, de acuerdo con el artículo 231 de la Constitución, ante el Tribunal Supremo de Justicia. Por su parte, al otro día, ese tribunal avaló la continuidad en sus funciones del gobierno, aunque el presidente Hugo Chávez no pudiese jurar el 10 ante la Asamblea Nacional y lo hiciera, más adelante, ante esa corte. De ese modo, los siete jueces consideraron que „el poder ejecutivo constituido (...) seguirá ejerciendo cabalmente sus funciones con fundamento en el principio de la continuidad administrativa". Por lo tanto, el vicepresidente Nicolás Maduro, designado por Chávez como su heredero político, seguiría en funciones, así como el resto del gabinete ${ }^{38}$. La decisión fue aceptada por el líder de la oposición Henrique Capriles, quien enfrentó a Chávez en las elecciones de octubre de 2012.

Los mensajes del gobierno y la decisión del tribunal abrieron fuertes dudas acerca del futuro de Venezuela y de su democracia, sobre todo a partir de que los jueces se hubieran negado a convocar una junta médica independiente para verificar la situación del presidente, cuya ausencia temporal podría derivar en una incapacidad para continuar en ejercicio de la presidencia. Por otro lado, dejó abierta la especulación de que podría estar clínicamente muerto - o muerto

\footnotetext{
${ }^{37}$ Chávez pidió eliminar palabra 'muerte’ del lema socialista, „El Tiempo”, 29/07/2011, $<$ http://eltiempo.com.ve/venezuela/gobierno/chavez-pidio-eliminar-palabra-muerte-del-lemasocialista/27866>, [consulta: 15/12/2012].

38 Tribunal Supremo avala continuidad del gobierno de Chávez, Capriles acepta, „Radio Nederland", 09/01/2013, <http://www.rnw.nl/espanol/bulletin/tribunal-supremo-avala-la-continuidaddel-gobierno-de-ch\%C3\%A1vez>, [consulta: 10/01/2013].
} 
- y legitimar la continuación del gobierno por parte del vicepresidente Maduro. En una nota de opinión, Gustavo Coronel lo planteó explícitamente:

¿Estamos ante el fraude del siglo?

Imagínese el lector si Hugo Chávez está muerto o clínicamente muerto y el régimen venezolano de Nicolás Maduro y Diosdado Cabello, con la complicidad del TSJ, del ejército venezolano, de la Asamblea Nacional de Venezuela, del Castrismo, de José Mujica, de Evo Morales, de Daniel Ortega, de Cristina Fernández, de José Miguel Insulza, de Gustavo Dudamel y José Antonio Abreu y de aquellos miembros de la oposición que se han acatado mansamente la violación a la Constitución, ha montado todo un sainete para ocultar esta situación a los venezolanos mientras logra consolidarse en el poder. ¿Cómo deberíamos reaccionar nosotros ante un fraude tan gigantesco? ¿Con una sonrisa de resignación o confrontando a los jefes de la pandilla y a sus cómplices en el terreno que sea?

Lo que no se quiere entender en Venezuela y en los sectores políticos invertebrados de América Latina es que la probabilidad de que un fraude de esta magnitud pueda estar en marcha tiene que ser esclarecida urgentemente. Un fraude tan gigantesco, de existir, es intolerable y sus responsables y cómplices deben ser objeto de un inmediato castigo ejemplar.

El silencio de los demócratas de la región es estruendoso ${ }^{39}$.

La situación así planteada no habla sólo de la calidad de la democracia venezolana sino de la de toda la región, ya que involucra a varios presidentes como parte una trama urdida para mantener vigente el régimen.

Al respecto y como una nota de color, en mayo de 2011, fue difundida a través de varios medios una foto del 15 de junio del año 2000 - época en la que Alberto Fujimori ya había sido reelegido por tercera vez - en la que Keiko Fujimori, la hija del presidente peruano y quien fuera candidata presidencial de „Fuerza 2011” - aparece bailando „El Trencito” con el presidente de la República Bolivariana de Venezuela, Hugo Chávez ${ }^{40}$.

El caso de Honduras también es revelador del estado de salud de la democracia en nuestros países. En la mañana 28 de junio de 2009 el presidente constitucional, Manuel Zelaya, fue destituido cuando personal de las fuerzas armadas irrumpió en su domicilio y lo expulsó del país. El origen de la crisis fue una consulta que promovió el presidente constitucional, en la cual se instalaría lo que se denominó una „cuarta urna” en las elecciones generales de noviembre de ese año. A través de la misma los hondureños decidirían la viabilidad de una convocatoria a una Asamblea Constituyente para reformar la Carta Magna del país. El Congreso, el poder judicial y sectores del ejército consideraron que la consulta era una „farsa” y que Zelaya sólo procuraba cambiar el marco jurídico para proceder a una reelección y perpetuarse en el poder. Por su parte, el presidente destituido negó esa versión y la comunidad internacional reaccionó inmediatamente

\footnotetext{
39 Gustavo Coronel Es probable que Hugo Chávez haya muerto, „Noticiero Digital”, 14/01/2013, <http://www.noticierodigital.com/2013/01/es-probable-que-hugo-chavez-haya-muerto/> [16/01/2013].

40 Difunden peculiar fotografia de Keiko Fujimori y Hugo Chávez, „LaRepublica.pe”, 17/05/2011, <http://www.larepublica.pe/17-05-2011/difunden-peculiar-fotografia-de-keiko-fujimori-yhugo-chavez $>$ [consulta: 28/12/2012].
} 
en su apoyo solicitando su restitución. Varios gobiernos de la región consideraron que se trató de un „golpe de Estado”, entre ellos los de Venezuela y Bolivia. Por su parte, la Unión Europea lo calificó de „golpe militar” y pidió que la reinstauración del orden constitucional y el secretario general de la Organización de Estados Americanos (OEA), José Miguel Insulza, convocó a una reunión urgente del Consejo Permanente para analizar la crisis y, „defender la estabilidad democrática" en Honduras ${ }^{41}$. El mismo día de la destitución de Zelaya se expidió la Comisión Interamericana condenando el golpe de Estado ${ }^{42}$.

Inmediatamente Zelaya fue sustituido por el presidente del Congreso Nacional, Roberto Micheletti, quien presidió interinamente el país hasta el 27 de enero de 2010, fecha de la toma de posesión de Porfirio Lobo, quien resultó electo en las elecciones celebradas el 29 de noviembre de 2009. Desde el 28 de junio de 2009 - y hasta la actualidad - el país no ha logrado estabilizarse, como lo demuestra la acusación que el presidente Lobo formuló en diciembre de 2012, por la que denuncia a dos medios de comunicación de conspirar contra su gobierno porque destacan en primera plana un comunicado de la Corte Suprema de Justicia y la posición de la Iglesia que exigen al Poder Ejecutivo respetar la independencia de poderes ${ }^{43}$.

La debilidad de las instituciones hondureñas se aprecia en la destitución de cuatro jueces de la Corte que habían declarado inconstitucional una ley y por el cerco que efectivos de las fuerzas armadas le impusieron al Parlamento en diciembre de $2012^{44}$. La destitución se hizo con el voto a favor de 97 de los 128 legisladores que integran el Congreso, mientras que los 31 restantes votaron en contra. La oposición se refirió al hecho considerándolo un "golpe técnico" contra el Poder Judicial e, incluso, lo comparó con el golpe de Estado de 2009 contra el presidente Manuel Zelaya. Como puede apreciarse, Honduras no ha logrado un equilibrio entre los tres poderes y las fuerzas armadas actúan inclinando la balanza a favor del Ejecutivo.

En Argentina, a mediados de la década de 1940 hizo irrupción en la política el coronel Juan Domingo Perón, quien se entronizó en el poder de manera democrática, gobernando al país entre 1946 y 1955, año en que fue

41 Golpe de estado en Honduras, „BBC Mundo”, 28/06/2009, <http://www.bbc.co.uk/mundo/america_latina/2009/06/090628_1430_honduras_arresto_med.shtml>, [consulta: 04/07/2009].

42 Sobre la posición de la Comisión Interamericana de Dērechos Humanos, ver el siguiente documento: Honduras. Derechos humanos y golpe de Estado, CDHI, OEA/Ser.L/V/II., Doc. 55, 30/12/2009, $<$ http://www.cidh.org/pdf\%20files/HONDURAS2009ESP.pdf $>$, [consulta: 13/12/2012].

${ }^{43}$ Lobo acusa a diarios de “conspirar" por publicar comunicado de Corte Suprema, „La Prensa” (Honduras), 07/12/2012, <http://www.laprensa.hn/Secciones-Principales/Honduras/Apertura/Lobo-acusa-a-diarios-de-conspirar-por-publicar-comunicado-de-Corte-

Suprema\#.UQqoeh2Tw18>, [consulta: 16/12/2012].

44 Congreso hondureño da ,golpe técnico" a la Corte, „Infobae”, 12/12/2012, <http://america.infobae.com/notas/63047-Congreso-hondureno-da-golpe-tecnico-a-la-Corte.html>, [consulta: 14/12/2012]. 
derrocado por un golpe militar - la denominada „Revolución Libertadora” encabezada principalmente por los altos mandos de la Armada Argentina. En su obra La opinión pública, el filósofo del derecho Carlos Cossio, al referirse a la motivación de su libro, dice que fue publicado en la revista jurídica La Ley, de Buenos Aires, de marzo a julio de 1957, buscando

un instrumento que me permitiera meditar con claridad sobre la situación política y social de mi país, después del derrocamiento de un cesarismo popular despótico que lo oprimió por casi una década, precedido por una dictadura reaccionaria que duró tres años y seguido por un gobierno de liberación acentuadamente negativo, durante un tiempo similar ${ }^{45}$.

Es claro que Cossio, al utilizar el término „cesarismo popular despótico”, alude al gobierno de Perón. No obstante, el personalismo en la Argentina se remonta a las guerras civiles que tenían como protagonistas a los caudillos de turno, v. gr., el „Chacho” Peñaloza, Facundo Quiroga o Juan Manuel de Rosas.

Hacia fines de la década del 1980 emergió la figura de Carlos Saúl Menem, quien gobernó el país durante los años 90 y que encontró trunco su proyecto de acceder a su tercer mandato en 1999, naufragando lo que - en ese momento José Pablo Feinmann definía como „el proyecto cesarista de Carlos Menem”46. En 1998 Feinmann se refería así a las intenciones del entonces presidente:

El proyecto cesarista de Carlos Menem surge de una cualidad (que no valoraremos aquí) que tiene todo jefe cesarista: una profunda egolatría, una certeza de ser único y de hacer todo lo necesario para serlo. Nuestro Presidente comanda un partido político que ya tuvo un gran jefe cesarista, un campeón del cesarismo que se llamó Juan Perón y fue tres veces presidente. Menem no tolera no igualarlo. Igualarlo para superarlo después. Si Perón se calzó tres veces la banda, él no será menos. Ser menos César que Perón es no ser César en absoluto. Así razona un cesarista ${ }^{47}$.

Feinman hablaba de la necesidad de Menem de „politizar la economía”, es decir, de hacer „populismo" para "salvar su pellejo” para cubrir ,en orden la inevitable y muy temida retirada" pero que el establishment fue el que le puso los límites porque no toleraría que „el costo de la re-reelección deteriore los logros de la macroeconomía”.

Tras la crisis de diciembre de 2001, la Argentina no ha logrado volver a una normalización de la democracia $\mathrm{y}$, desde entonces, se asiste a una creciente debilidad institucional. En 2003 asumió la presidencia Néstor Kirchner quien, promediando su mandato, comenzó a dar muestras de cierto autoritarismo. Si bien al finalizar el mismo podía presentarse a la reelección, su proyecto consistió en la reelección alternada con su esposa, la senadora Cristina Fernández de Kirchner, quien asumió tras las elecciones de 2007. Tras haber perdido en las elecciones parlamentarias de 2009 , el proyecto de alternancia se

\footnotetext{
${ }^{45}$ Carlos Cossio, La opinión publica. Buenos Aires, Paidós (4a edición), 1973, p. 15.

46 José Pablo Feinmann, Cesarismo, „Página 12”, 04/04/1998, <http://www.pagina12.com.ar/1998/98-04/98-04-04/contrata.htm>, [consulta: 28/12/2012].

${ }^{47}$ Ídem.
} 
quebró con la muerte de Néstor Kirchner en octubre de 2010. La presidente decidió presentarse en las elecciones siguientes.

En las elecciones presidenciales de 2011 Cristina Fernández de Kirchner triunfó con el $54 \%$ de los votos, según la versión oficial, porcentaje que es utilizado con suma frecuencia para argumentar las decisiones que se toman en el gobierno, aún a costa del resto de las instituciones y de las demás minorías que integran la sociedad argentina. Respecto de ese porcentaje, se hace necesario aclarar que el caudal de votos que recibió la presidente en ejercicio, en realidad, representaba el $40 \%$ del electorado habilitado para emitir el voto. De tal manera que el $54 \%$ surge de los votos positivos, es decir que no se tienen en cuenta los votos en blanco ni los anulados.

Con referencia a la debilidad institucional, un ejemplo de ello son los fallos de la Corte Suprema que no fueron acatados por el Poder Ejecutivo Nacional - como es el caso en el que la Corte estableció, en el fallo Betancour, que las jubilaciones no pueden ser inferiores al $70 \%$ del sueldo promedio al momento en que el trabajador se retira de la actividad -, ni por el Poder Ejecutivo de la Provincia de Santa Cruz - donde se establecieron los Kirchner durante el gobierno militar, donde hicieron su fortuna y construyeron su poder político -, por ejemplo, en lo que respecta a la restitución en su cargo del ex procurador de esa provincia, Eduardo Sosa, quien fue echado por Néstor Kirchner en 1995, cuando era gobernador de esa provincia. La Corte Suprema falló en 2009 y para los ministros de la misma, el incumplimiento por parte del gobierno de Santa Cruz, ,constituye un desconocimiento del principio de división de poderes". En 2010, el tribunal denunció penalmente al gobernador santacruceño. Cabe agregar que el jefe de gobierno de la Ciudad Autónoma de Buenos Aires, Mauricio Macri, tampoco ha cumplido con ciertos fallos de la Corte Suprema.

Ante la imposibilidad de continuar con el proyecto de alternancia en la presidencia, debido a la muerte de Néstor Kirchner, sectores afines al gobierno desearon instalar la necesidad de una reforma constitucional para poder impulsar un tercer mandato de Cristina Fernández de Kirchner. Uno de los partidarios de esta propuesta, el ministro de Planificación Federal, Julio de Vido, afirmó que la presidente en ejercicio es su „candidata” y „la mejor opción" para las elecciones de 2015. Además, afirmó que la modificación de la Carta Magna „bajo ningún aspecto es lesiva para la vida democrática, todo lo contrario" $^{48}$. Esta intención quedó trunca ante la rotunda derrota oficialista en las elecciones primarias legislativas celebradas en agosto de 2013.

Cabe agregar que el filósofo José Pablo Feinmann - a quien mencioné más arriba por criticar al presidente Menem por su proyecto reeleccionista,

48 De Vido vuelve a postular a Cristina para 2015: 'Es la mejor opción', „La Nación”, 01/02/2013, <http://www.lanacion.com.ar/1550906-de-vido-vuelve-a-postular-a-cristina-para-2015-esla-mejor-opcion>, [consulta: 01/02/2013]. 
calificándolo de „cesarista” - no juzga de la misma manera las intenciones del actual gobierno y se caracteriza por hacer uso de unas expresiones que dejan en claro su verticalismo hacia la figura de los Kirchner o, peor aún, su desmedida obsecuencia. En ese sentido, no se ha privado de criticar a quienes se consideran opositores del gobierno, llegando a expresar que quienes odian a Cristina Fernández de Kirchner „lo hacen por envidia” ${ }^{49}$. Por propio pundonor me ahorro citar la extensa referencia a la envidia y los elogios a la presidente realizados por Feimann.

El 11 de marzo de 2011 el proyecto alternativo de los Kirchner fue tomado por el presidente de Guatemala y su esposa. Con la intención de llevarlo a cabo, el presidente Álvaro Colom y su esposa, Sandra Torres, iniciaron el proceso de divorcio para habilitarla como candidata presidencial. Con anterioridad, ante la sospecha de la oposición de que ese sería el camino para asegurarse la continuidad, el matrimonio y sus partidarios lo negaron ${ }^{50}$.

\section{A MODO DE CONCLUSIÓN}

La historia reciente de la democracia en América contrasta notoriamente con lo que Alexis de Tocqueville pudo observar en su visita a los Estados Unidos en la primera mitad del siglo XIX.

Podría profundizar la narración de esa historia pero llevaría, también, a una profundización de los ejemplos que ponen en evidencia la baja calidad institucional de nuestros países. Además de los mencionados, se podrían citar las frustradas aspiraciones a la reelección de Álvaro Uribe, en Colombia, o los intentos de que en Perú los Fujimori retornasen al poder a través de Keiko. En este último caso, como en el de la Argentina de los Kirchner o la Guatemala de los Colom, se apela a que sólo los miembros de una familia están en condiciones de gobernar un país, siguiendo el modelo del venezolano Juan Vicente Gómez. Este sólo pensamiento sirve para denostar al resto de la sociedad y, entre ellos, a aquellos virtuosos - entendiendo la virtud en el sentido aristotélico - que podrían ejercer el gobierno con mayor decoro y sentido nacional que estos líderes. El ejemplo de Cuba, en el que Fidel Castro le pasó el mando a su hermano, Raúl Castro, no es dable citarlo en este contexto ya que se trata de „sucesiones” que se llevan a cabo en democracia.

\footnotetext{
${ }^{49} \mathrm{Al}$ respecto ver: José Pablo Feinmann y su explicación sobre el odio a Cristina, „La Nación”, 01/10/ 2012, <http://www.lanacion.com.ar/1513334-jose-pablo-feinmann-y-su-explicacion-sobre-elodio-a-cristina>, [consulta: 02/10/2012].

${ }^{50}$ Esposa de Álvaro Colom ,,lo deja” por Presidencia, „La Prensa” (Nicaragua), 22/03/2011, $<$ http://www.laprensa.com.ni/2011/03/22/internacionales/55577-esposa-lvaro-colom-deja $>$, [consulta: $24 / 03 / 2011]$.
} 
En el caso argentino la „tiranía de la mayoría” está en esa permanente recurrencia al ,54\%" que permitió la reelección de Cristina Fernández de Kirchner. En Venezuela Chávez habló del ,socialismo del siglo XXI” y en la Argentina los Kirchner nos muestran el ,peronismo del siglo XXI”, con algunas diferencias respecto del peronismo de Duhalde y del peronismo de Menem, este último totalmente diferente del peronismo de Perón. ¿Qué pretendo expresar con estos diferentes peronismos? Que no hay ideología sino intereses por parte de los líderes, quienes sólo recurren a lo que les conviene de la historia para perpetuarse en el poder. Chávez lo hace con Simón Bolívar y los argentinos con Perón, el cesarista del siglo XX. Los Kirchner invocaron a Eva Perón y a ellos mismos a partir de la construcción de un relato que intenta imponer una nueva historia argentina que, prácticamente, parecería comenzar en 2003.

No hay un „ismo” si no hay ideología, sólo son conceptos vacíos. En el caso argentino eso se comprueba con la forma en que el líder de turno, quien se asume como peronista, ejerce el poder. Lo mismo es válido para el jefe de gobierno de la Ciudad Autónoma de Buenos Aires, quien a veces apela a esa imagen porque, en definitiva, el peronismo aporta un gran caudal de votos. Meterse debajo del "paraguas del peronismo" y ser aceptado como el „caudillo" por la masa - con el alineamiento de los demás referentes del Partido Justicialista -, parece ser el camino seguro para ganar las elecciones.

La mención del „travestismo político” del filósofo José Pablo Feinmann quien tildó de cesarista a Menem pero ha devenido en un „ultrakirchnerista”, a pesar de tener enfrente un proyecto casi idéntico - le cabe a numerosos referentes del peronismo que han acompañado los ,diversos tipos de peronismo". Les cabe también a muchos otros que hoy se encuentran como funcionarios del gobierno, quienes critican las gestiones de Alfonsín, Menem, De la Rúa y Duhalde pero de cuyos gobiernos formaron parte. Son muchas veces esos funcionarios quienes alientan la continuidad del „César” por temor a perder las prerrogativas obtenidas. La lista de estos funcionarios sería extensa pero cabe agregar que también la masa de los votantes actúa de la misma manera y dan continuidad a una serie de gobernantes que sólo procuran la perpetuación en el poder. A propósito de esto, vale mencionar al periodista Rolando Hanglin cuando, en un artículo titulado „Carta abierta del Sr. González: con la reelección, ¿vuelven los reyes?”, recuerda la expresión del revolucionario brasileño José Bonifacio de Andrada: „El populacho ensoberbecido es más tirano que el rey absoluto”. Luego continúa: „Algo parecido pensaba San Martín, a quien ha homenajeado la Masonería Argentina: 'Nada hay más grave que la turba integrada por personas que no tienen nada, decididas a quitarles todo a los dueños...'. Parece ser que San Martín entró a esa institución en 1808, invitado por su jefe, su ídolo, el Marqués de Solano, que 
murió linchado en Cádiz en ese mismo año. ¡Por afrancesado! O sea, simpatizante de la Libertad, la Igualdad y la Propiedad Privada"51.

De ese modo, la masa que sostiene al „César” avala sus actitudes, las cuales retroalimenta por medio de la exteriorización de sus pasiones. Quien ose disentir con el „César” no sólo será vapuleado por éste sino también por sus „cívicos sostenedores” y esto se refleja muchas veces cuando se manifiesta algún líder de la oposición en contra alguna medida de gobierno o de alguna manifestación del gobernante o de algún funcionario. El disenso es considerado como una traición, quien disiente es considerado „destituyente", es decir, quien pide la caída del gobierno o ,golpista”.

Estas apreciaciones, así como la encuesta realizada en Perú a los veinte años del autogolpe de Alberto Fujimori - que revelaba que 4 de cada 10 peruanos consideraba esa medida como necesaria - hablan a las claras no sólo de la calidad de la democracia sino también de los propios votantes. Los ciudadanos no valoran a la democracia en sí misma sino que por encima de ella valoran al „líder". En la actualidad, en casos como en la Argentina y Venezuela, se asiste al culto a la personalidad lo que nos lleva a repensar el título del artículo de Hanglin de si „con la reelección, ¿vuelven los reyes?”. Si esta es la tendencia, estaríamos camino a la instalación de una „monarquía electiva” decidida por lo que en política se denomina una „mesa chica” - los pocos decisores que toman las medidas en una agrupación política - la cual decide cuál candidato de la familia ha de seguir gobernando y proponerlo al pueblo para que lo elija por voto popular y legitime, de esa manera, la continuidad del régimen. En el caso venezolano no se trata de alguien de la familia sino de un „delfín” designado por el „César”. Tanto en un caso como en el otro, la sucesión genera incertidumbre. En la Argentina, para mantener la continuidad se hace necesario modificar la Constitución para permitir la reelección de cara a las elecciones de 2015 o, caso contrario, designar un „delfín” de la presidente porque sino aparecerá un nuevo candidato del peronismo que tendrá que aglutinar las huestes del partido, en realidad del „movimiento” que es capaz de ser oficialismo y oposición al mismo tiempo. El caso de Venezuela es más complejo por la gravedad de la enfermedad de Chávez, por lo que algunos consideraban que Maduro lo necesitaba en coma $^{52}$ mientras que otros acuerdaban que un desenlace fatal del „César" podía favorecer electoralmente a Maduro, como una réplica del escenario argentino tras el fallecimiento de Néstor Kirchner. Una tercera posibilidad era que Maduro perdiera las elecciones frente a un Capriles que podía incrementar su caudal de votos frente a una „copia difusa” de Chávez.

\footnotetext{
${ }^{51}$ Rolando Hanglin, Carta abierta del Sr. González: con la reelección, ¿vuelven los reyes?, en: La Nación, 28/12/2012, <http://www.lanacion.com.ar/1502993-carta-abierta-del-sr-gonzalez-con-lareeleccion-vuelven-los-reyes $>$, [consulta: 28/12/2012].

52 Iván R. Méndez, Maduro lo necesita en coma, en: Analítica.com, 29/01/2013, $<$ http://www.analitica.com/va/politica/opinion/6425551.asp>, [consulta: 30/01/2013].
} 
En cualesquiera de los escenarios de ambos países se percibe un agotamiento del „cesarismo democrático” y, si la salida para nuestros países es la monarquía, pues entonces que no sea „electiva” sino real - en su doble acepción - y ser prácticos como el libertador José de San Martín, quien se decidió por esa forma de gobierno si es que la única meta de la revolución era la emancipación de España. En 1829, cuando dos enviados del general Juan Lavalle viajaron a Montevideo para ofrecerle el gobierno, en momentos en que se aprestaba a retornar a Europa, les expresó: „Es conocida mi opinión de que el país no hallará jamás quietud, libertad, ni prosperidad sino bajo la forma monárquica de gobierno. En toda mi vida pública he manifestado francamente esta opinión, de la mayor buena fe, como la única solución conveniente

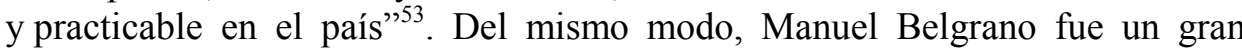
defensor de la monarquía: „Es casi general la opinión de la monarquía constitucional. Han perdido casi totalmente el campo los del republicanismo". Abrir un debate acerca de si la monarquía podría ser una futura forma de gobierno para la Argentina podría ser sumamente enriquecedor, sobre todo si observan las ventajas que tendría frente a una „monarquía electiva”.

Dejando de lado esta digresión, es posible que - dada la situación - la continuidad esté zozobrando pero debido a la idiosincrasia de buena parte de los miembros de nuestras respectivas sociedades, del arraigo de la idea de que es necesario que un „caudillo" lidere la nación y la afición a los partidos que apelan al populismo, es altamente probable que la historia se repita y asistamos - musicalmente hablando - a variaciones sobre un mismo tema. En este sentido, es apropiado citar nuevamente a Tocqueville:

Lo que más confusión provoca en el espíritu es el uso que se hace de estas palabras: democracia, instituciones democráticas, gobierno democrático. Mientras no se las defina claramente y no se llegue a un entendimiento sobre su definición, se vivirá en una confusión de ideas inextricable, con gran ventaja para los demagogos y los déspotas ${ }^{54}$.

De la misma manera me parece oportuno citar a José Ortega y Gasset:

La forma que en política ha representado la más alta voluntad de convivencia es la democracia liberal. Ella lleva al extremo la resolución de contar con el prójimo y es prototipo de la „acción indirecta”. El liberalismo es el principio de derecho político según el cual el poder público, no obstante ser omnipotente, se limita a sí mismo y procura, aun a su costa, dejar hueco en el Estado que él impera para que puedan vivir los que ni piensan ni sienten como él, es decir, como los más fuertes, como la mayoría. El liberalismo - conviene hoy recordar esto - es la suprema generosidad: es el derecho que la mayoría otorga a la minoría y es, por tanto, el más noble grito que ha sonado en el planeta. Proclama la decisión de convivir con el enemigo: más aún, con el enemigo débil ${ }^{55}$.

\footnotetext{
${ }^{53}$ Carlos Ibarguren, San Martín intimo. Buenos Aires, Peuser, 1950, p. 208.

${ }^{54}$ Alexis de Toqueville, El Antiguo Régimen y la Revolución (2 vol.). Madrid, Alianza, 1982, p. 100.

${ }^{55}$ José Ortega y Gasset, La rebelión de las masas. Madrid, Espasa Calpe, 2006, p. 141.
} 
La coincidencia de José Ortega y Gasset con Tocqueville con referencia al respeto que la mayoría debe tener respecto de la minoría es absoluta.

A partir de lo expuesto, se hace imprescindible difundir el civismo, en sus dos acepciones, como „celo por las instituciones e intereses de la patria” y como „comportamiento respetuoso del ciudadano con las normas de convivencia pública", así como también las virtudes democráticas de las que habló Tocqueville en La democracia en América, como la ,igualdad de condiciones”, la „igualdad de oportunidades”, la „defensa de la libertad individual” y la importancia de la división de poderes.

En su época Tocqueville le transmitió a sus contemporáneos las ventajas de la forma democrática de gobierno y, particularmente, la necesidad de „los contrapesos" para que la democracia no derive hacia la tiranía o hacia el despotismo.

De lo contrario, esta cuestión coyuntural se transformará en una cuestión estructural; sobrevivirá el imaginario del „caudillo” por encima de la democracia, la debilidad del Estado y de las instituciones y un desdibujado sistema de partidos políticos. En este esquema el papel que asuma la oposición será trascendente para revertir el camino de ,involución democrática” que la región transita luego de tres décadas de haber recuperado, no sin esfuerzo individual y colectivo, el sistema democrático para nuestras naciones.

El arco político en su conjunto será responsable de perpetuar esta crisis del sistema democrático o de encaminar nuestras sociedades hacia el concepto de „comunidad” que señala Zygmunt Bauman, aquel que produce una „sensación” positiva, aquel que la muestra como algo bueno y „cálido” en donde desearíamos vivir. La comunidad en la que podamos convivir.

\section{THREATS TO DEMOCRACY IN TOCQUEVILLE. „THE TYRANNY OF MAJORITIES” IN MODERN TIMES}

Summary. This article is addressed to Tocqueville's vision regarding the virtues of democracy in the United States, particularly regarding the ,iqual conditions” but also refers to threats that can affect that form of ruling: the possibility of falling into despotism and tyranny of majorities.

From that point it analyzes how these two threats advance in American democracies and, at present, have given rise to talk of ,neopopulism”, which refers to the existence of net populist governments in the past. Several American nations went through this kind of politics, which has left serious consequences both to political parties, institutions and in the respective societies. After overcoming the military governments that dominated the political life of the region and after the return of democracy, the author considers that populism has become entrenched again in the form of government in many countries.

Key words: Tocqueville, democracy, Caesarism, populism, neopopulism 